\title{
Strategic Recruiting: A Human Resource Management Case Study
}

Lynn M. Murray, Pittsburg State University, USA

Arthur K. Fischer, Pittsburg State University, USA

\begin{abstract}
This is a Human Resource Management (HRM) case used to encourage student thought and discussion following a class segment on recruiting. Midwest Education, Inc.: A Human Resource Management Case is used to exemplify many of the human resource problems encountered in a typical complex organization. It provides history and background of the company, Midwest Education, Inc. (which is closely modeled after a major developer and supplier of educational materials). The case presents the three major divisions of the company and shows how each is following a different strategy. With this background, the case presents the current problems which arise as the company seeks to change from ad hoc recruiting practices to a planned, strategically aligned process. As the case develops, it is seen that corporate headquarters is challenging the HR directors of each of the operating divisions to address recruiting issues through a systematic approach. Readers are challenged to determine what issues are most pressing during the recruiting process, and to develop comprehensive recruiting plans for the divisions.
\end{abstract}

Keywords: HRM case; recruiting; strategy

\section{INTRODUCTION}

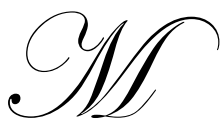

idwest Education, Inc. is a major supplier of educational materials for the United States. The company focus is on learning tools and systems for use in technology, science and business classrooms. In addition, it develops and provides books, manuals, videos, software and hardware used in the fields of technology education, instructional development and business applications.

The company has its headquarters and primary manufacturing plant in a major Midwest community. In addition, the Creative Development offices are located in Massachusetts and California. Transportation, Service and Maintenance facilities are headquartered out of Texas, with major branches in Baltimore and Phoenix.

The three main divisions exemplify three different strategies: c ost-reduction, quality enhancement, and innovation (as discussed by Schuler and Jackson, 1987).

\section{Transportation, Service and Maintenance}

The primary strategy of the Transportation, Service and Maintenance Division is cost-reduction. Midwest Education, Inc. has long been known for providing service and maintenance programs which are very reasonably priced.

\section{Manufacturing}

The primary strategy of the Manufacturing Division is quality enhancement. Midwest education, Inc. has an enviable history of providing the highest quality products which have been adopted by first-rate schools and corporate training programs. 


\section{Creative Development}

The primary strategy of the Creative Development Division is innovation. Midwest Education, Inc. is widely known for providing truly cutting edge teaching materials which always mirror the latest techniques and processes.

\section{COMPANY HISTORY}

Midwest Education was started by Henry and Mary Dalton in 1975. Dr. Henry Dalton was an industrial arts teacher before he got his MBA and went on to get his Ph.D. in Technology Education. Mary was a software developer who also taught business seminars. At that time a new wave of emerging technology was beginning to alter the way people learn and communicate. By developing Midwest Education, Inc. the Daltons began work in an exciting new field. They found a vast market for quality tools that educated people on how to use all the new technology. Dr. and Mrs. Dalton are in semi-retirement now and travel extensively, but remain major shareholders in the business. They personally hired the CEO when they went into semi-retirement.

The company started with about fifty employees, but has grown consistently and now has a total of 416 employees within its three major divisions: 183 employees work in the Manufacturing Division, 123 work in the Creative Development Division and 135 work in the Transportation, Service and Maintenance Division. There are also 71 employees working at the headquarters in Kansas City (including the corporate staff).

At the beginning on the 1990s it became apparent that international business was becoming the rule rather than the exception. The company went international in 1994 and now is exporting to three European, two Latin American, and two Pacific Rim countries. The Global Operations Division is located within the headquarters.

\section{Headquarters}

The corporate headquarters are in Kansas City. The CEO of Midwest Education, Inc. is Judith Lund. Ms Lund was hired by the Daltons in 1994 when they decided to take a less active role in the company while remaining major shareholders. Ms. Lund has an MBA in business management, and was previously the CEO of a small telecommunications company. In her previous position, Ms Lund had successfully steered the company out of financial difficulties by raising stock value. She had initiated a strong advertising campaign and had put the company 'in the black' for the first time in seven years.

The COO of Midwest Education, Inc. is Frank Rose. Frank has been with the company since 1989. Mr. Rose, a cousin of Dr. Dalton, had a successful career with an international business training group in California. His desire to move back to his home town of Kansas City came at a time when the Daltons were looking for a COO. He has worked out well for the company.

The Human Resources Department is also located at the headquarters. The Vice President for Human Resources is Lawrence Wilson. Mr. Wilson has a degree in industrial and organizational psychology and an MBA. He has been with the company for 11 years. He started out as a generalist and was promoted as he showed good judgment with hiring and earned his MBA at the same time.

Within the Human Resources Department there are four sections:

1. Staffing, the head of this section is Patrick Shew.

2. Compensation and benefits section, headed by Michael Martin.

3. Labor management relations section, headed by Keith Lane.

4. Training, career development and performance appraisal section, headed by Cynthia Burns.

There are also human resource specialists in each of the three divisions around the country. 


\section{Manufacturing Division}

The mission statement for the Manufacturing Division is:

The aim of the Manufacturing Division of Midwest Education, Inc. is to continually improve the quality and strength of all our products. The superior products for which we have become world renowned will still be manufactured along with new and innovative products and ideas. We will work hard to keep quality high and cost down while supplying customers with the best possible products in the shortest possible time. The Manufacturing Division follows a strategy of quality enhancement.

The main manufacturing plant is located on the outskirts of Kansas City, not far from the company headquarters. The president of the Manufacturing Division is Max Thorn. Mr. Thorn has been with the company almost since its inception. He was one of the first employees hired by the Daltons. He started writing programs for the company and originally worked alongside the Daltons in interviewing and hiring many other employees.

The head of human resources for the Manufacturing Division is Janine Woods. She has a staff of five generalists who assist her in meeting HRM needs for the Manufacturing Division.

The Manufacturing Division used to be housed in the same building as the headquarters. As the business expanded and more room was needed, the division moved to the suburbs into a large factory site. There are 158 employees in the Manufacturing Division. They are divided into ten teams, each team works at producing and packaging a specific product at a time. There are five supervisors who each supervise two teams: Doris Malone, John Fizer, Sandi Cross, Wendy Atchison, and Ian Carpenter.

The Manufacturing Division usually has a long lead time on orders and can anticipate what will be needed. The factory has flexible work areas that can be re-tooled and rearranged for the changeover from one product to another in less than four hours. The pay in this Division starts at $\$ 6.25 / \mathrm{hr}$ for production workers and has a full benefits package. Most employees seem happy with their work. Max Thorn is generally thought of as a good, easy-going man to work for.

\section{Creative Development Division}

The mission statement for the Creative Development Division is:

In the Creative Development Division of Midwest Education, Inc. we will strive to bring our customers the most innovative and cutting edge programs and products in the world. Our team of creative professionals is constantly working to improve, upgrade, and create the most useful products to bring to our customers. This division follows a strategy of innovation.

The Creative Development Division has two locations; a headquarters in California and a branch located in Massachusetts. The president of the Creative Development Division is Serena Tibaldo. Ms. Tibaldo recently joined the company. Previously she was a software developer for a large computer game producer. She has a bachelor's degree in business and a computer programming master's degree, and is doing very well at Midwest.

The head of human resources for the Creative Development Division is Amelia Chi, who is located at the California headquarters. Ms. Chi has a staff of five assistants. The head of the human resource section at the Massachusetts branch is Virginia Fox. Ms Fox has a staff of two assistants.

There are 90 people employed at the California plant and 38 at the Massachusetts location. The California location opened in 1980 and the Massachusetts branch was opened in 1993. In the 1970's and 1980's many computer software programmers moved to the west coast to be located in Silicon Valley. Most people hired by Midwest Education, Inc. transferred from wherever they lived to the California branch, with the company paying all relocation expenses. By 1990 some employees desired to live in the east. The Daltons decided it was time to expand the company and in doing so decided the next branch would be in the Massachusetts area. Most of the long time 
elected to remain California. The majority of recent hires are in Massachusetts.

\section{Transportation, Service and Maintenance Division}

The mission statement for the Transportation, Service and Maintenance Division is:

The Transportation, Service, and Maintenance Division is committed to providing the fastest and most cost effective way of safely shipping our product to our customers. No effort will be spared as we streamline and improve our fast and friendly service. The Transportation, Service and Maintenance Division follows a strategy of cost-reduction.

The Transportation, Service and Maintenance Division headquarters is located in San Antonio, Texas. There are major branches in Baltimore, Maryland and Phoenix, Arizona. The President of the Transportation, Service and Maintenance Division is Mark Derrick. Mr. Derrick is based in San Antonio. Mr. Derrick has been with Midwest Education, Inc. for 13 years. He personally hires the managers for the other branches in Maryland and Arizona.

The head of human resources for the Transportation, Service and Maintenance Division is Salvador Vasquez. Mr. Vasquez has a staff of five assistants. Mr. Vasquez appoints HR heads to the other branches. Often they are employees from San Antonio that he knows well and trusts.

The Transportation, Service and Maintenance Division was originally based in Kansas City. As the company grew a decision was made to relocate the division to Texas. The other branches are newer, with Maryland opening in 1989 and Arizona in 1996. There are 55 employees in San Antonio, and 40 in each of the other two branches.

\section{SITUATION - Recruiting Case}

As the company grew, it relied predominately on referrals from existing employees and ad hoc recruiting. Now, however, the pace of growth and acquisitions has outpaced the ability of Midwest Education to rely on these methods. The HR department has been tasked with developing recruiting plans to hire employees who will prove to be long-tenured, productive employees - in other words, employees who fit the corporate culture of Midwest and its various divisions. This task is further complicated by the differing skills, abilities, and output required by each division. Wilson and his staff have met to discuss the needs of each division in its recruiting efforts.

"Welcome to Kansas City - I know for some of you, August in KC is a sweltering change from the usual.

"We've got a big task ahead of us. By the end of this week I'd like to have a preliminary recruiting plan for each division to take to the executive committee meeting scheduled for late next week. Our agenda for today's session is to talk about the requirements of each division and brainstorm how we might target each division's recruiting efforts. I want to emphasize that we will not be abandoning our reliance on hiring referrals from current employees - in fact, I'd like us to play with some way of systemizing our referrals and encouraging more. Let's go ahead and get started. Janine [HR director for the Manufacturing Division] can you tell us about our manufacturing needs?"

Janine: "Thanks, Lawrence. I think our staffing and recruiting requirements are pretty basic. We have about 160 positions on the line. These are divided into ten teams with each team focusing on manufacturing and packaging a specific product. When we hire for these positions, we aren't looking for previous experience as much as we are looking for the ability to work with a group. I rarely actively recruit externally. We really rely on current employee referrals to fill any empty position. Not only do I tend to get a better employee, but the referring employee will help ensure that the new employee is successful -- peer pressure can be a great thing!"

"I am starting to see some issues with my hiring of supervisors. We are starting to see more Hispanic immigrants (legal, of course) on the lines, and I'd like to reflect that in my front-line supervisors, whether through promotions or new hires. We know that recruiting for Hispanic persons can be quite different, largely because of the role their family orientation plays." 
"One last thing: one of the reasons we don't see much turnover in our line people is because of Max. He really sets the tone in the division and our staff likes working for him. We don't differ in our pay or benefits from other places our employees could work. What makes the difference is the culture at the plant. We really need to emphasize this in our recruiting efforts and the different activities we pursue."

"Thanks, Janine," Wilson said. "Your current situation seems well-in-hand; however, please consider what it would mean if we were to increase production by $25-40 \%$. Could you handle the staffing requirements through referrals?"

Janine looked very doubtful. "OK. Start thinking about how you might recruit applicants for new positions - both line and supervisory. Amelia, you're up."

Amelia Chi [head of HR for the Creative Development Division]: "Our situation in Creative differs significantly from Manufacturing. We strive for innovation, and we need to hire for a combination of creativity and programming skills. We look for evidence of these in previous projects, types of experience, and training and education. I've got three big issues: making the right hire, developing the right work environment, and office space."

"My biggest concern is making the right hire - these folks aren't only high salaries, they're also expensive to source and recruit. I need to somehow make sure they have the skills and abilities we need and to make sure they can fit into our work environment."

"I also have to make sure that I can keep those creative and programming juices flowing. These aren't typical 95 ers - they tend to work crazy hours and are demons for sugar, caffeine, and games.

"My final concern is office space. As you know, our division is located in two of the most expensive locales in the country - Silicon Valley and Massachusetts. I'd like to explore some telecommuting options as well as job-and office-sharing arrangements."

"Finally, I'd like to explore the possibility of using contract employees. This could be a way for us to provide a realistic job preview for prospective employees and for us to get to know them before we hire them permanently."

Wilson turned next to Salvador Vasquez [director of HR for the Transportation, Service and Maintenance division]. "You're up, Sal."

Salvador Vasquez. "Thanks, Lawrence. Our focus in TSM is on cost efficiency - 'we ship cheap' is our unofficial motto. We've found that inexperience hurts: we hire people who have warehouse and trucking experience, but we also need people who can work with automation, as we have automated as much as possible. We tend to get the best hires for our warehouse positions when we hire a supervisor from another distribution center (whether its a center like Wal-Mart or Sysco) and the new supervisor brings his or her best people along. "

"What we try to do is to keep processes and working conditions in each of our three branches as similar as possible - it helps that Mark [Derrick, president of TSM] hires managers for all the branches."

"As to being ready for an increase of $25-40 \%$ of product moved, we already operate at capacity. We'll need to hire more people and increase our investment in capacity."

Wilson put his pen down and stood and stretched. "Let's take a break. We'll reconvene in 15 minutes and start brainstorming."

STUDENTS will be divided into teams, with each team analyzing a different division. Each team will address the following needs for its division:

1. Provide a summary of the HR concerns and challenges of the division.

2. Outline a recruiting plan for the division. What activities would be most important? Why?

3. What external recruiting activities should the division use if workload picks up and the company needs to grow? 


\section{FOR THE INSTRUCTOR}

Specific questions might be addressed for each division (e.g. Manufacturing - How would you develop a referral program for the division? Creative Development - What are the advantages and disadvantages to using contract staff? and For which positions is a realistic job preview most appropriate? Why?)

\section{AUTHOR INFORMATION}

Dr. Lynn Murray is an Assistant Professor of Marketing in the Department of Management and Marketing at Pittsburg State University. She has worked in the hospitality industry for firms such as YUM! and Disney, and in areas such as advertising sales representative and human resources recruiter. In her teaching she emphasizes learning and application through the use of live cases.

Dr. Art Fischer is a University Professor of Management in the Department of Management and Marketing at Pittsburg State University. He is a FELLOW with the American College of Healthcare Executives, and is a retired healthcare executive. 